\title{
Avaliação das condições de acessibilidade a partir da percepção dos usuários no prédio do Centro de Engenharias - Alfândega
}

\section{Assessment of accessibility conditions from user perception in the Centro de Engenharias Building - Alfândega}

\begin{abstract}
BRUNO COELHO MENDES
Bacharel em Engenharia de Produção, Universidade Federal de Pelotas, brunocmrs@gmail.com

ITALO RODEGHIERO NETO

Doutorando em Engenharia de Produção, Universidade Federal do Rio Grande do Sul, italorneto@gmail.com

MAYARA ZANCHIN

Mestre em Ciências, Universidade Federal de Pelotas, maayfrizzo@gmail.com

DOUGLAS DE CASTRO BROMBILLA

Doutorando em Arquitetura e Urbanismo, Instituto Federal do Rio Grande do Sul, douglas.brombilla@riogrande.ifrs.edu.br
\end{abstract}

ISABELA FERNANDES ANDRADE

Doutora em Arquitetura e Urbanismo, Universidade Federal de Pelotas, acessiarq@gmail.com

\section{RESUMO}

A legislação brasileira estabelece que as edificações de uso público ou espaços de uso coletivo devem ser acessíveis a todas as pessoas. Logo, edificações construídas no passado e que recebem novos usos, devem se adequar as novas leis vigentes. Dessa forma, este trabalho visa expor as condições de acessibilidade do Prédio do Centro de Engenharias - Alfândega, a partir da percepção dos usuários. Aplicou-se o método denominado passeio acompanhado com cinco indivíduos, sendo possível obter um panorama das condições de acessibilidade do Prédio da Alfândega, confrontando as distintas acerca do ambiente construído, além da relação entre os problemas identificados e a legislação que rege sobre a preservação do patrimônio histórico. Apesar de identificarem quase todos os ambientes requisitados, os participantes do passeio acompanhado avaliaram a acessibilidade na edificação como ruim/mediana. Todos os participantes sugeriram a implementação de placas de orientação/identificação em diferentes ambientes do prédio, bem como a colocação de um mapa de localização em seu hall de entrada. Por fim, são apontadas recomendações de intervenções para a 


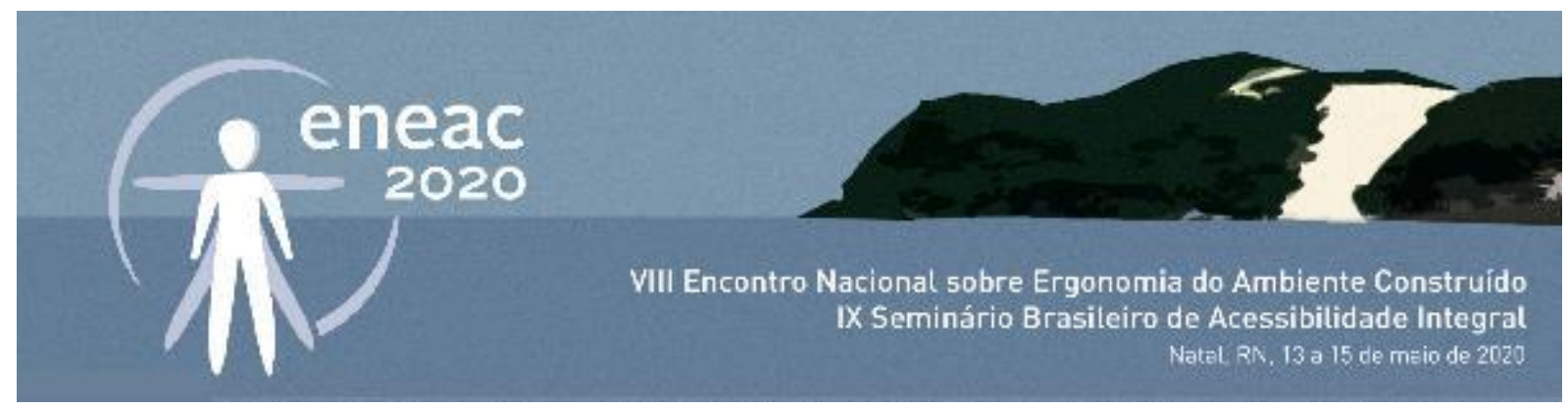

garantia de melhores condições de acessibilidade, como a instalação de placas e rampas. Ainda, sugere-se a continuidade de estudos acerca do tema.

PALAVRAS-CHAVE: Acessibilidade espacial, passeio acompanhado, ambiente universitário

\begin{abstract}
Brazilian law provides that public buildings or collective spaces must be accessible to all. Therefore, buildings built in the past and receiving new uses must adapt to the new laws in force. Thus, this paper aims to expose the accessibility conditions of the Engineering Center Building - Alfândega, from users' perception. It was applied the method called accompanied walk (DISCHINGER, 2000) with five individuals, being possible to get an overview of the accessibility conditions of the Alfândega Building, comparing the differences about the built environment, besides the relationship between the identified problems and the legislation that governs the preservation of historical heritage. Despite identifying almost all the required environments, the participants of the accompanied walk rated accessibility in the building as poor/median. All participants suggested the implementation of orientation/identification signs in different environments of the building, as well as the placement of a location map in their lobby. Finally, recommendations are made for interventions to ensure better accessibility, such as the installation of slabs and ramps. Still, we suggest the continuity of studies on the subject.
\end{abstract}

KEYWORDS: Spatial accessibility, accompanied walk, university environment

\title{
1 INTRODUÇÃO
}

Com o decorrer dos anos, a necessidade de tornar ambientes acessíveis torna-se cada vez mais relevante. Porém, ainda é entendido por grande parte da população que acessibilidade se restringe apenas às pessoas com deficiências, muito embora este seja um direito de todos os cidadãos.

Para Andrade (2009), a acessibilidade está relacionada ao ato de projetar edifícios, cidades e produtos que possam ser utilizados com conforto, segurança e autonomia por todas as pessoas, independentemente de suas capacidades ou limitações, de forma igualitária. Sendo assim, espaços que não contemplam os requisitos mínimos que possibilitam o acesso a todas as pessoas acabam limitando seu uso por pessoas com deficiências e com mobilidade reduzida.

Outro conceito bastante utilizado associado a acessibilidade aos ambientes é o de acessibilidade espacial (DISCHINGER et al., 2012). Segundo Bins Ely (2004), "acessibilidade espacial significa bem mais do que poder atingir um lugar desejado. É também necessário que o local permita ao usuário compreender sua função, sua organização e relações espaciais, assim como participar das atividades que ali ocorrem.". Todas essas ações devem ser realizadas com segurança, conforto e independência. Sendo assim, para um melhor entendimento deste tema, as autoras dividem o conceito em quatro componentes: orientação espacial, comunicação, deslocamento e uso.

A orientação espacial trata das características que o ambiente dispõe para que o indivíduo possa ter uma compreensão do espaço em que se situa, para que tenha um deslocamento ideal no local. A comunicação refere-se às possibilidades de troca de informações interpessoais, ou troca de informações entre pessoas e equipamentos de tecnologia assistiva que permitem o acesso, a 


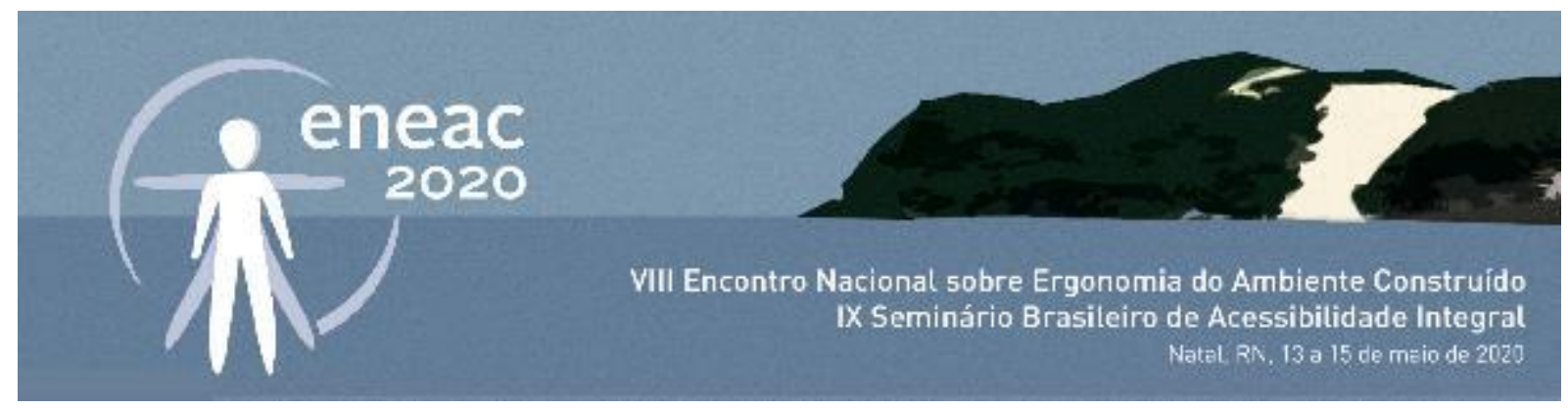

compreensão e participação nas atividades (DISCHINGER et al., 2012). O deslocamento refere-se à capacidade de qualquer indivíduo de movimentar-se no ambiento, ao longo de percursos horizontais e verticais de forma independente, segura e confortável (DISCHINGER et al., 2012). Por fim, o componente uso refere-se a participação de todo e qualquer indivíduo nas atividades, possibilitando a todos a interação com qualquer objeto. Neste quesito é importante levar em conta as dimensões, relevo, textura e cores dos móveis, assim como a posição dos mesmos.

Com o passar dos anos, evidenciou-se que edificações antigas não contemplavam condições de acessibilidade adequadas para receber a sociedade como um todo. Para isso, foi necessária a criação de leis e normas para que as pessoas, deficientes ou não, pudessem ter um livre acesso a todos os prédios. Pautar-se na legislação e na normatização é importante para garantir a igualdade e o direito de locomoção e uso do espaço construído (COSTA; DE ARAÚJO, 2014). Assim, a Norma Brasileira 9050 (2015) e a Norma Brasileira 16.537 (2016), por exemplo, são regulamentações que visam estabelecer diretrizes para que os ambientes se tornem mais acessíveis a todas as pessoas (RODEGHIERO NETO, 2018).

A utilização de prédios antigos para diferentes finalidades em relação àquelas para os quais foram construídos acarreta, muitas vezes, um problema que pode ser observado na grande maioria dessas edificações: a falta de acessibilidade. Nas Instituições de Ensino Superior (IES) o problema não é diferente, pois o estudante com deficiência é privado, em muitos casos, de utilizar todos os espaços em função da falta de ambientes acessíveis. A Universidade Federal de Pelotas (UFPel), por exemplo, adquiriu uma série de edificações que, quando construídas, não tinham o uso destinado às Instituições de Ensino.

Quando o prédio do Centro de Engenharias - Alfândega foi construído, em 1938, os parâmetros de acessibilidade não eram considerados - a primeira legislação sobre o tema no Brasil data do ano de 1985. Contudo, conforme o Decreto-Lei Federal 5.296 (2004), todas as edificações de uso público teriam prazo para se adaptar às leis de acessibilidade até junho de 2007. Mais de dez anos se passaram e ainda temos condições bastante precárias nesse sentido.

Além disso, muitas das edificações mencionadas são protegidas por órgãos de preservação e, com isso, as intervenções a fim de torná-las acessíveis são dificultadas. No município de Pelotas, existem muitos prédios preservados pela Lei 4.568 (2000), atual instrumento legal utilizado pelo poder público para determinar a salvaguarda do patrimônio cultural, diferenciando os imóveis inventariados através de níveis de preservação.

O imóvel a que este estudo se propõe a investigar está elencado no nível dois de proteção de prédios inventariados, ou seja, garante-se o direito à preservação de sua fachada e volumetria arquitetônica, porém a área interna pode ser alterada. No entanto, o uso institucional traz consigo problemas relacionados à acessibilidade, pois pode-se considerar que o mesmo não foi projetado para abrigar salas de aula e laboratórios.

Segundo Costa e Meira (2010), embora se suponha que as instituições de ensino superior, no papel de educadoras, devam constituir-se como modelos a serem seguidos pela sociedade, percebe-se que o direito à educação superior tem sido negado ou restringido para muitas pessoas com limitação oriundas de deficiência. Em suma, isso ocorre devido à falta de acessibilidade ofertada pelas instituições de ensino. A relevância do presente estudo é evidenciada na avaliação dos principais problemas de acessibilidade identificados nesta edificação, tanto interna quanto externamente, a fim 


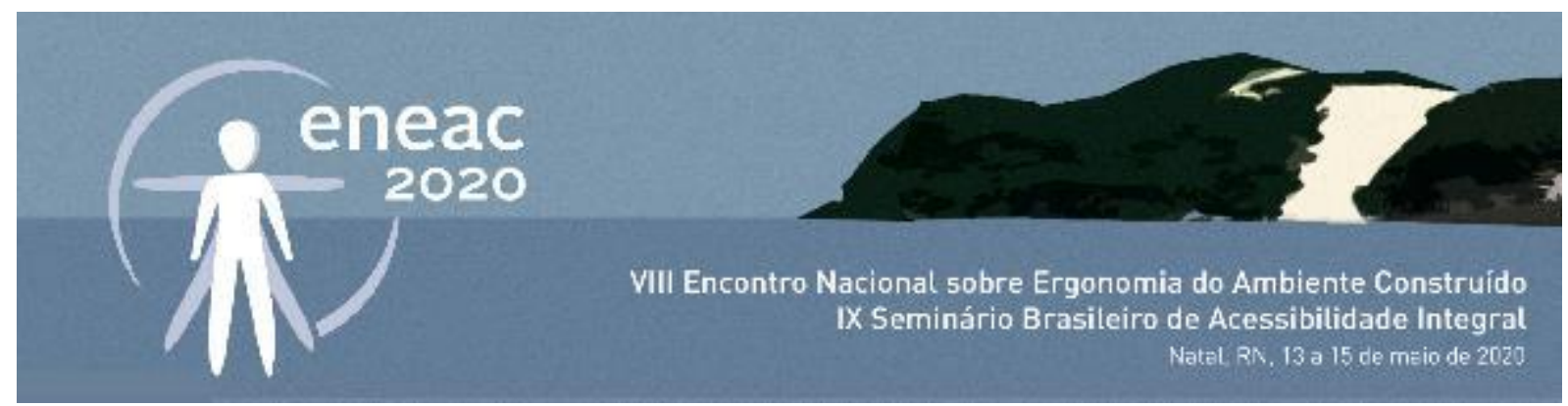

de propor sugestões de melhorias e/ou adaptações a fim de torná-la acessível.

. Sendo assim, o objetivo deste trabalho é expor as condições de acessibilidade no prédio do Centro de Engenharias - Alfândega, sob o ponto de vista dos usuários da edificação, reconhecendo as necessidades espaciais dos diferentes indivíduos. Assim, pode-se considerar que a originalidade deste trabalho está na avaliação da acessibilidade, por pessoas com diferentes características, frente a um ambiente antigo que é, desde 2008, utilizado para fins divergentes daqueles que foi projetado. Para isto, buscou-se utilizar o método passeio acompanhado, desenvolvido por Dischinger (2000).

\section{METODOLOGIA}

\section{1 ÁREA DE ESTUDO}

O objeto de estudo do presente trabalho é o Prédio do Centro de Engenharias - Prédio da Alfândega (Figura 01). Localizado na região portuária da cidade de Pelotas, a edificação teve momentos de movimento intenso, quando mercadorias chegavam constantemente na região Sul do Rio Grande do Sul.

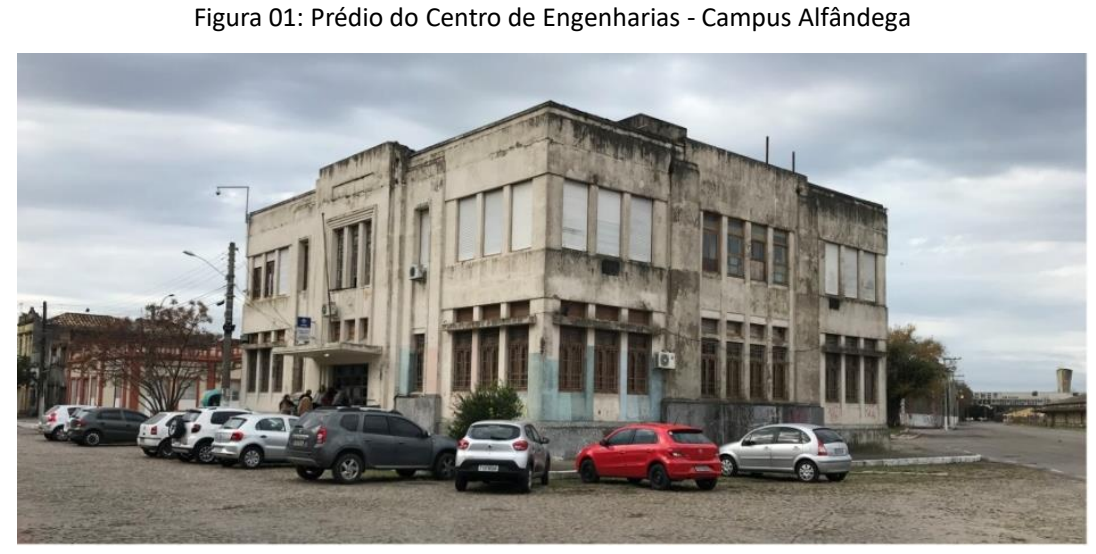

Fonte: Autores (2018).

Em 2010, a Universidade Federal de Pelotas adquiriu o imóvel para torná-lo parte do Centro de Engenharias. Após o período de reformulação, o espaço recebe os cursos de Engenharia Geológica, de Petróleo e Geoprocessamento. A partir do mesmo ano, o local foi reformado e readequado para sua nova função.

\subsection{PASSEIO ACOMPANHADO}

Este método, desenvolvido por Dischinger (2000), tem como objetivo obter informações sobre as dificuldades enfrentadas pelas pessoas com deficiência ou mobilidade reduzida frente ao espaço, a partir da realização de um roteiro pré-determinado pelo avaliador. Segundo Rodeghiero Neto (2018), 


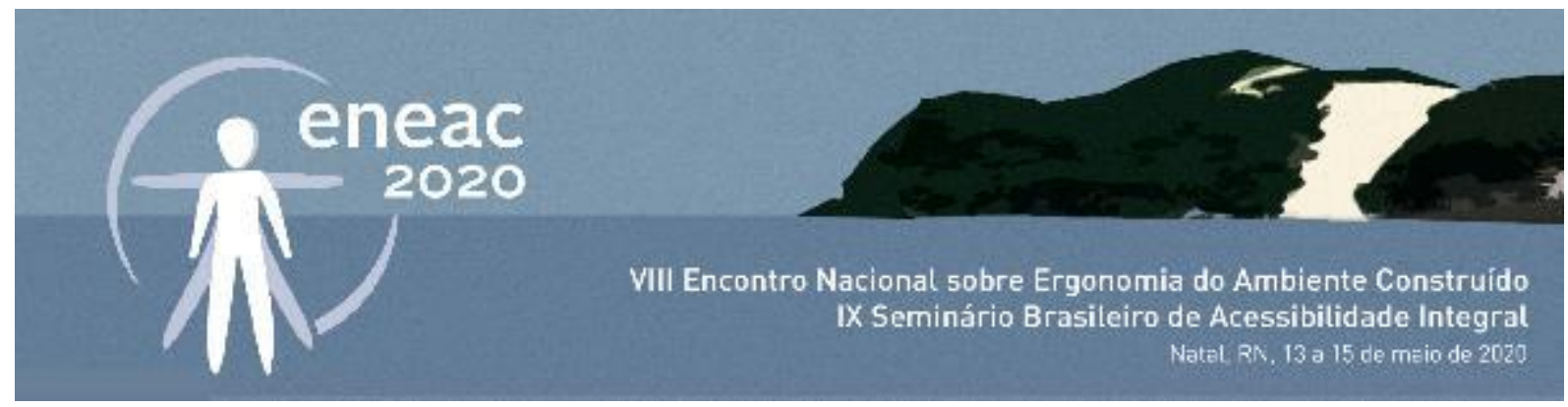

trata-se da realização de um roteiro por um indivíduo com alguma restrição ou não, que pode ou não conhecer o ambiente estudado.

O método foi aplicado com cinco participantes: um aluno da instituição que estuda na edificação em análise, um indivíduo com restrição temporária, um aluno da instituição que não conhecia a edificação, pai e filha (carrinho de bebê) e um indivíduo com baixa visão. $O$ roteiro elaborado pelo avaliador conta com as etapas de entrada no prédio, identificação de alguns locais de importância como balcão de informação, salas de aula e banheiro, chegando ao final do roteiro e a saída da edificação (Figura 02).

Figura 02: Roteiro elaborado para o passeio acompanhado

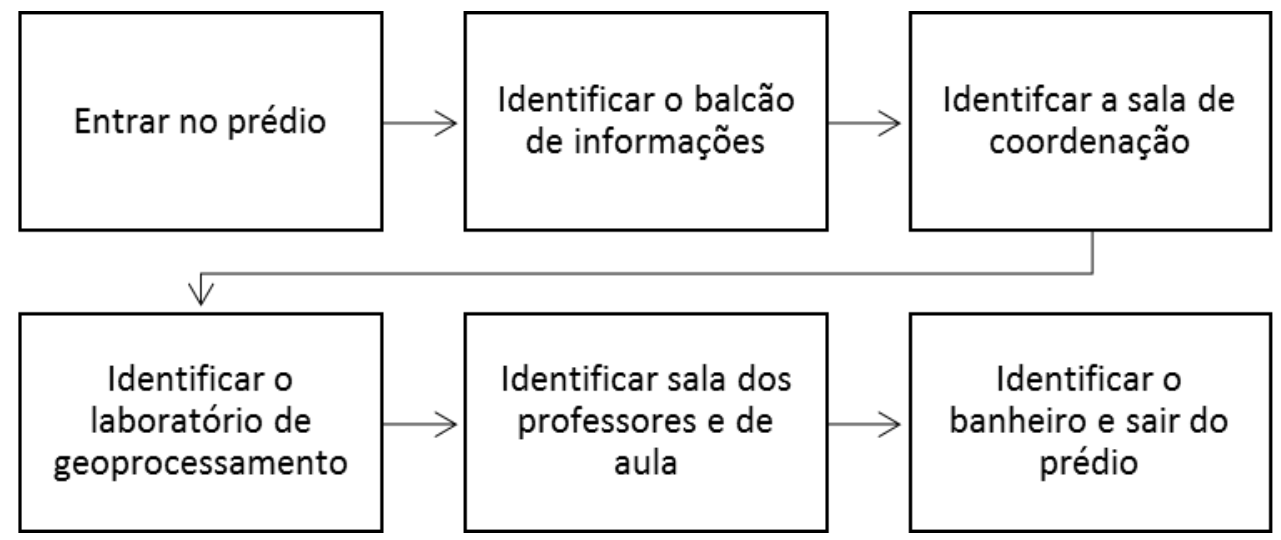

Fonte: Autores (2018).

O entrevistador deve sempre acompanhar o entrevistado, mas nunca interferir na rota e nem nas escolhas do mesmo. Durante a entrevista, questionou-se o usuário sobre como ele se sentia frente ao espaço e sobre as informações que eram apresentadas no local (DISCHINGER, 2000). Com autorização do entrevistado, todo o percurso foi gravado e, posteriormente, transcrito. Ao final dos percursos foram realizadas três perguntas aos participantes da atividade:

- Como você considera as condições de acessibilidade da edificação?

- Quais as possíveis melhorias em relação à acessibilidade do prédio?

- Foi possível deslocar-se de forma independente, segura e autônoma?

\section{RESULTADOS}

A partir do roteiro pré-elaborado e apresentado na metodologia, os participantes realizaram as atividades propostas. Foram obtidos os resultados oriundos dos cinco passeios com diferentes indivíduos, sendo realizados em dias distintos. Todos os participantes deram início à atividade na 


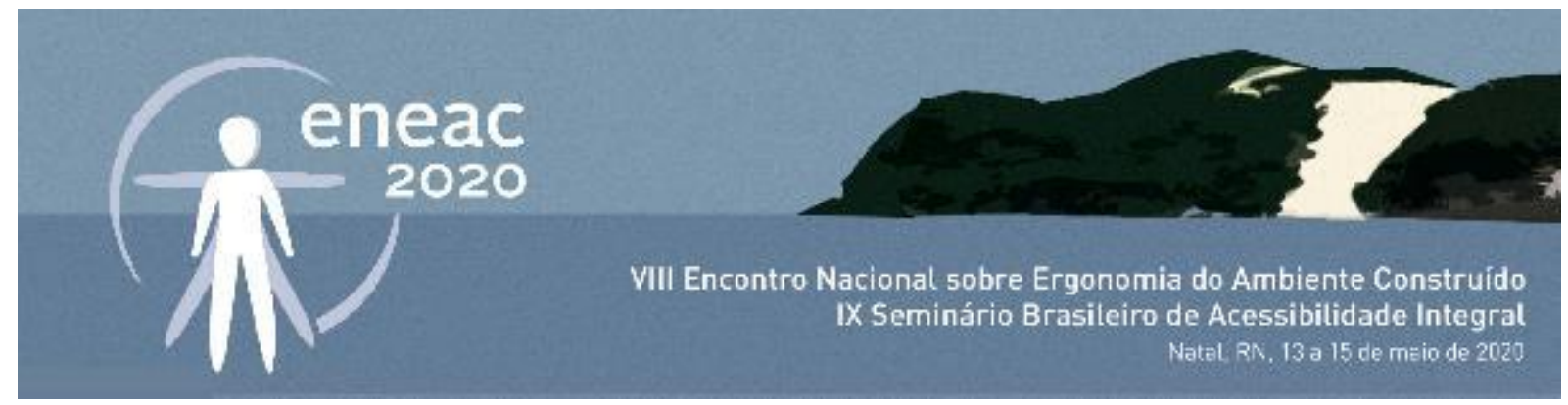

entrada do prédio, com exceção do Passeio 4, por tratar-se de uma pessoa com carrinho de bebê, pois o acesso a calçada da edificação só pode ser realizado na parte de trás do prédio.

\subsection{PASSEIO 1: ALUNO QUE JÁ CONHECIA A EDIFICAÇÃO}

O primeiro passeio foi realizado com um estudante de Engenharia, que já havia cursado disciplinas no prédio em análise, não possuindo nenhuma deficiência aparente. Como o aluno costumava frequentar a edificação no decorrer da graduação, as atividades foram realizadas com certa facilidade (Figura 03), sendo o passeio realizado em cinco minutos.

Figura 03: Primeiro participante identificando sala de aula e escadarias

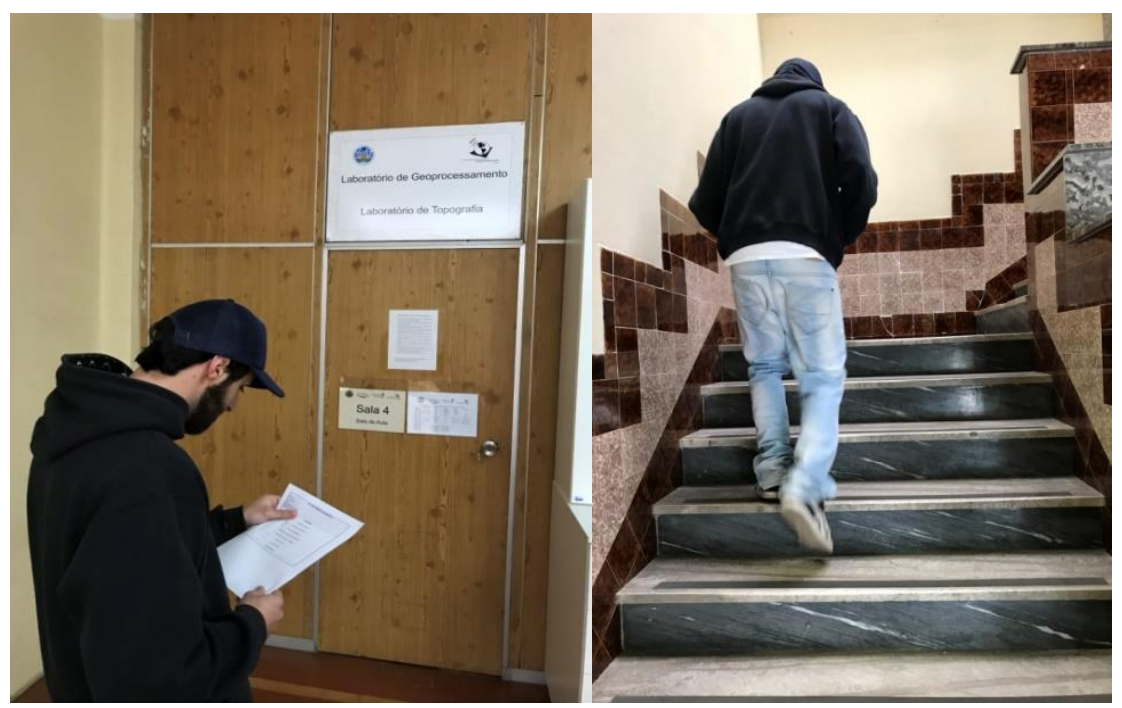

Fonte: Autores (2018).

Apesar de conhecer o ambiente, o participante teve dificuldade em identificar o banheiro no primeiro andar, observando que não há placas indicativas no interior do prédio. No entanto, durante o passeio, o estudante apontou que as escadas são bem visíveis e estão devidamente seguras para utilização por qualquer pessoa. Ainda, verificou que é possível deslocar-se no prédio sem obstáculos.

Ao final do trajeto, o participante deu duas importantes sugestões para a melhoria de acessibilidade da edificação. A primeira diz respeito às placas informativas, enfatizando que não há nenhuma placa indicativa no Prédio da Alfândega, o que faz com que pessoas que não utilizam o prédio tenham problemas para encontrar os ambientes requisitados. Além disso, sugeriu que a sala de coordenação deveria estar situada no primeiro andar da edificação, para que as informações transmitidas pelos coordenadores possam ser obtidas com maior facilidade.

Por fim, o participante observou que as condições de acessibilidade do prédio são precárias, e que grandes reformas seriam necessárias para o uso de pessoas com deficiência. 


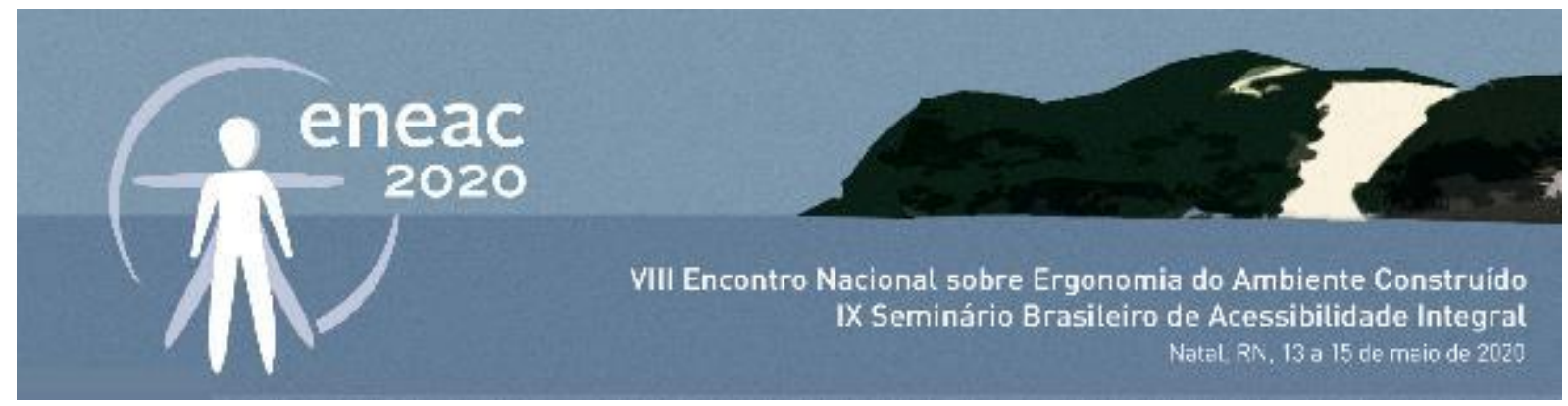

\subsection{PASSEIO 2: INDIVÍDUO COM RESTRIÇÃO TEMPORÁRIA}

O segundo passeio foi realizado com uma pessoa que apresenta mobilidade reduzida temporária: em virtude de uma queda, o participante utiliza muletas por tempo indeterminado. $O$ indivíduo não conhecia o prédio e não havia utilizado o local anteriormente, concluindo a atividade proposta em 10 minutos.

O passeio foi realizado com dificuldade, pois a edificação contém muitas escadarias, como é possível observar na Figura 04, não tendo certeza de que conseguiria realizar o roteiro completo. $O$ balcão de informações foi encontrado com sucesso. Porém, após demonstrar fadiga ao procurar a sala de coordenação, o mesmo optou por perguntar aos servidores do prédio onde essa se encontrava, não tendo localizado no primeiro andar da edificação. Após conversar com os funcionários, optou por seguir o roteiro e continuar a procurar os ambientes no segundo andar.

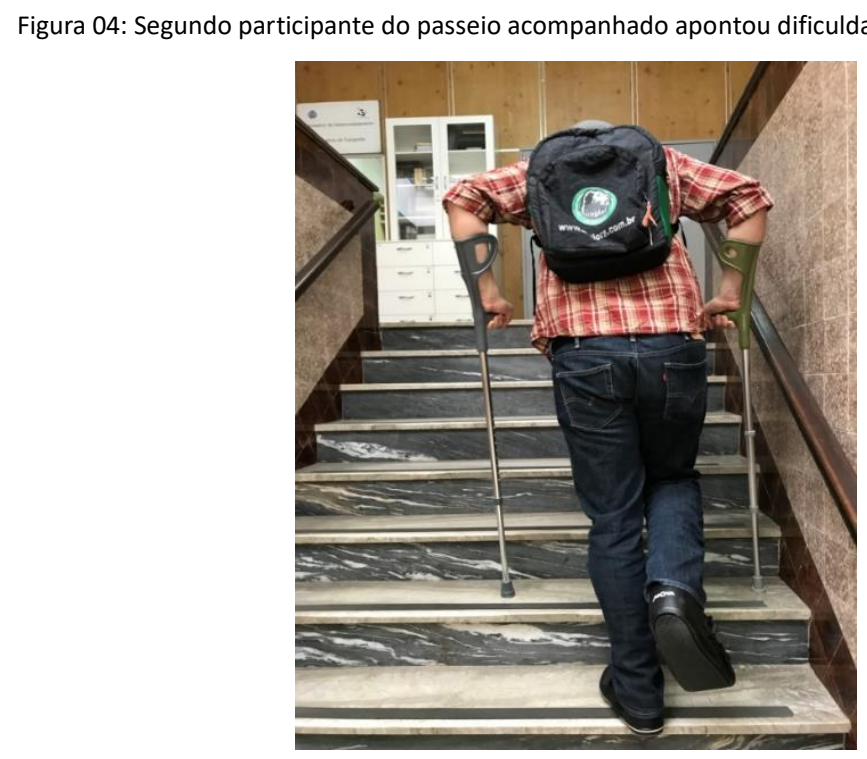

Fonte: Autores (2018).

Todos os ambientes do segundo pavimento foram encontrados com sucesso. Após identificar todos os locais do roteiro, o participante sugeriu melhorias para o Prédio da Alfândega. Em relação à escadaria, aconselhou a inserção de fitas antiderrapantes e corrimãos ao longo da escada. Apesar de considerar as condições de acessibilidade da Alfândega ruins, o entrevistado comentou que conseguiu deslocar-se no ambiente sem dificuldades.

\subsection{PASSEIO 3: ALUNO QUE NÃO CONHECIA A EDIFICAÇÃO}

O terceiro passeio ocorreu com um estudante da Instituição, sem deficiência ou limitação aparente. Apesar de estudar na Universidade, o aluno nunca havia utilizado o campus da Alfândega, sendo a atividade concluída em seis minutos. 


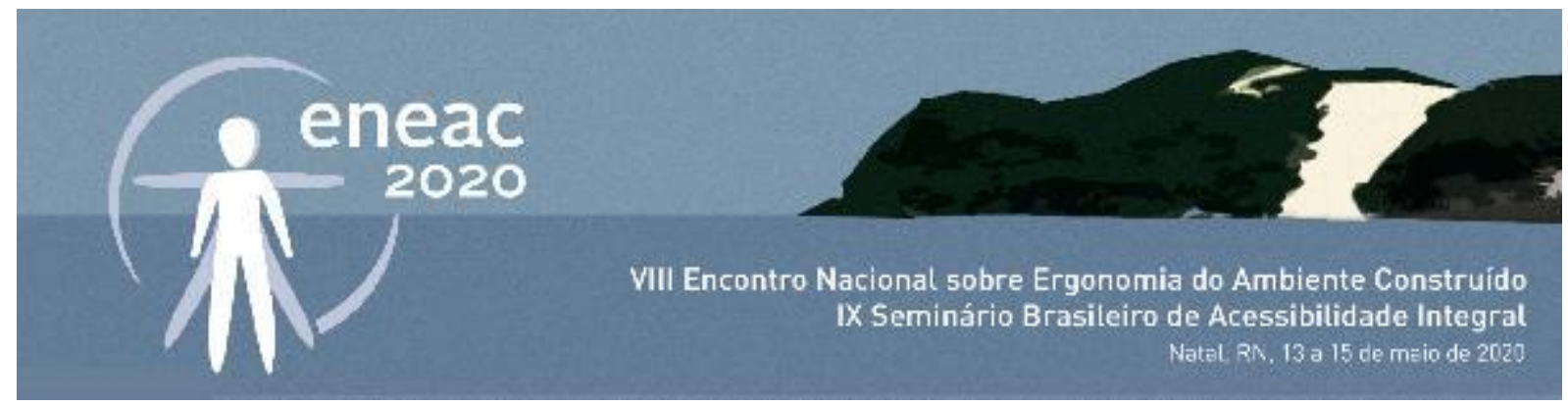

Apesar de não conhecer o local, o participante obteve facilidade para identificar os ambientes solicitados (Figura 05), com exceção do Laboratório de Geoprocessamento - sugerindo que placas fossem colocadas em tamanhos maiores e com cores contrastantes, como forma de ampliar a atenção dos usuários do prédio para elas.

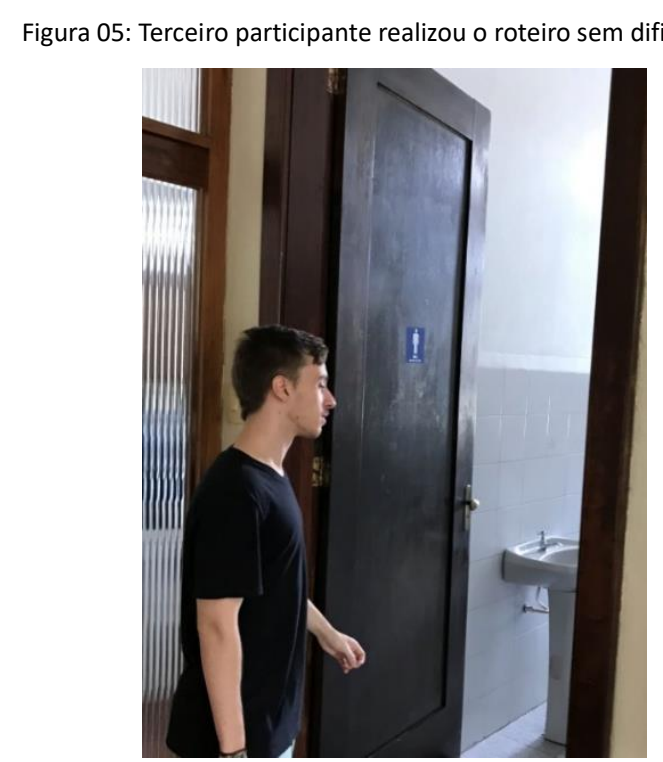

Fonte: Autores (2018).

Ao completar o trajeto, o participante indagou sobre a utilização do edifício por pessoas com deficiências ou mobilidade reduzida, definindo as condições de acessibilidade da Alfândega como medianas, visto que ele conseguiu realizar grande parte do que foi requisitado sem ajuda de outras pessoas.

Como sugestão de melhoria da acessibilidade da Alfândega, o estudante sugeriu a implementação de elevadores e rampas no acesso ao prédio. Outro ponto sugerido foi a instalação de um mapa de localização no hall de entrada do prédio, para que os usuários possam se localizar sem ajuda de terceiros.

Por fim, o participante disse não ter encontrado obstáculos que não permitissem sua livre movimentação durante o passeio, porém comentou que se sentiu perdido em parte do trajeto.

\subsection{PASSEIO 4: INDIVÍDUO COM CARRINHO DE BEBÊ}

Este passeio foi realizado com uma pessoa sem deficiência ou limitação temporária. A atividade ocorreu com um indivíduo junto de sua filha, que participou sendo transportada em um carrinho de bebê. O passeio foi realizado apenas em parte do roteiro pré-estabelecido, pois não há equipamento para a transposição da escada, única forma de circulação vertical na edificação. Sendo assim, somente os ambientes do primeiro andar foram demandados ao pai para serem localizados. A atividade foi finalizada em nove minutos.

Como o Prédio da Alfândega não possui rampas na calçada do acesso a edificação, o participante 


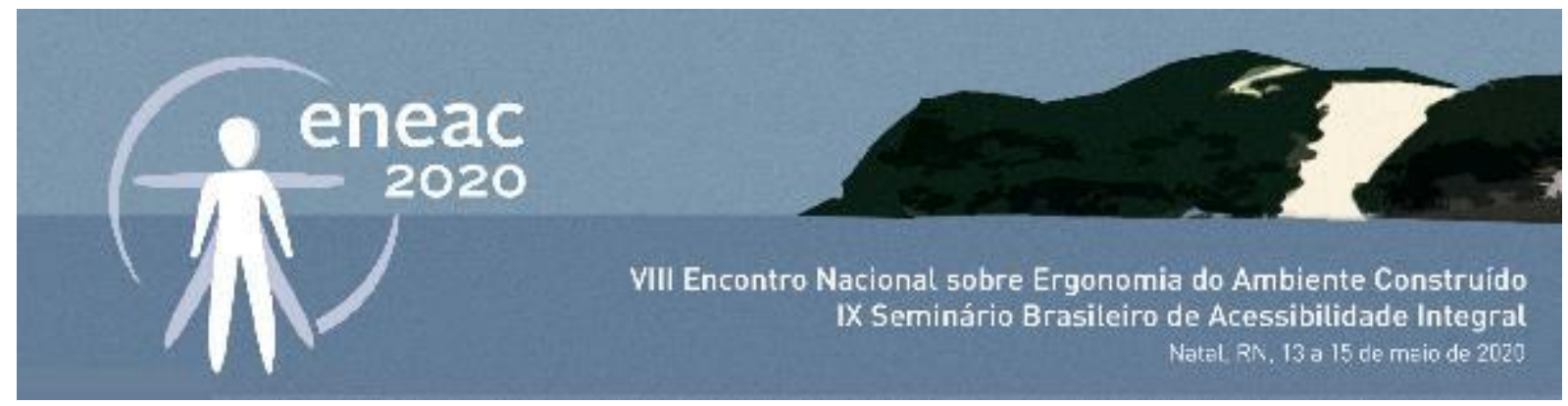

somente pôde começar a realizar o trajeto na parte de trás do prédio, em que existe uma rampa construída para dar acesso aos carros em uma garagem, como pode ser observado na Figura 06. Ao começar as atividades do roteiro, o indivíduo retratou que as calçadas não são planas, fazendo com que manobras tenham que ser realizadas para chegar à entrada do prédio.

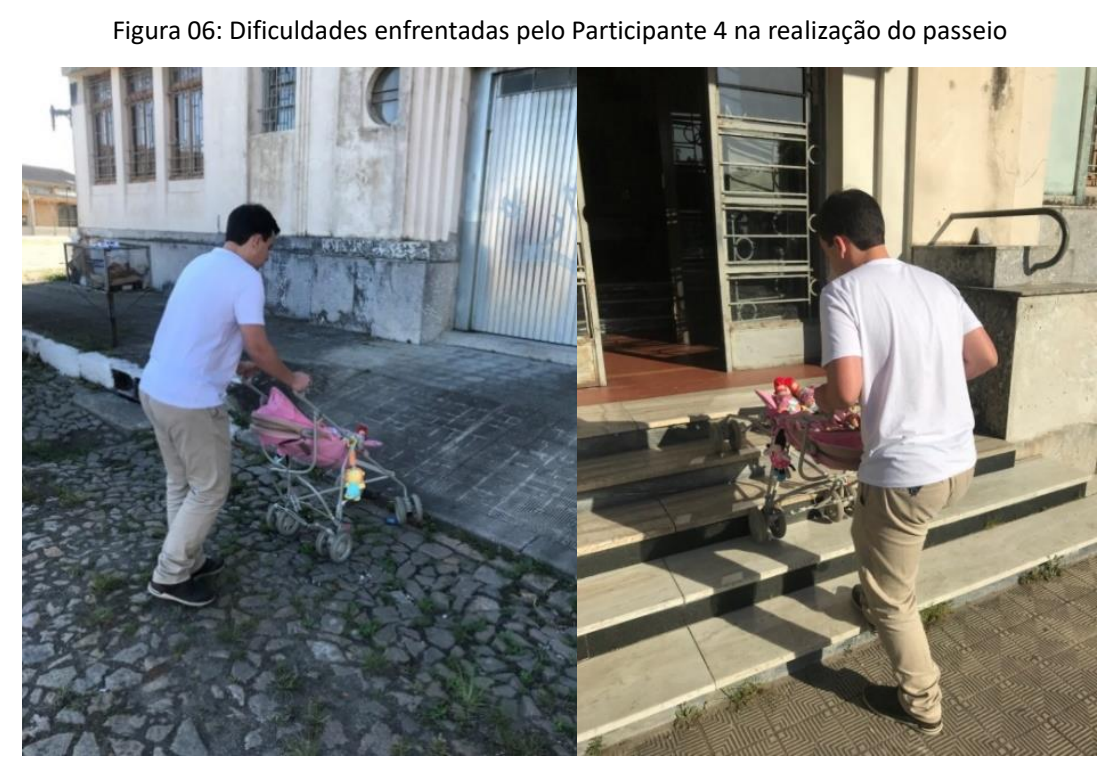

Fonte: Autores (2018).

Ao chegar na entrada da edificação, o participante teve muita dificuldade para subir a escada de acesso ao prédio, como demonstrado na Figura 06. A instalação de uma rampa no acesso ao prédio é de suma importância, segundo o indivíduo. As atividades propostas do roteiro no primeiro andar foram realizadas com facilidade. Porém, a saída do Prédio foi mais complicada que a entrada do mesmo, pois a manobra de saída exigiu que o participante se retirasse de costas não tendo plena visibilidade do local.

Finalizado o passeio, o participante comentou ter achado as condições de acessibilidade do Prédio da Alfândega ruins, pois não conseguindo deslocar-se com independência durante o trajeto, levando em conta que estava acompanhado de sua filha. Ao ser questionado sobre melhorias em relação à acessibilidade, disse que o primeiro passo a ser dado é a criação de rampas de acesso.

\subsection{PASSEIO 5: INDIVÍDUO COM BAIXA VISÃO}

O último passeio foi realizado com um estudante da Instituição que não conhecia o Prédio da Alfândega, com baixa visão. $O$ trajeto foi realizado sem auxílio de equipamento de tecnologia assistiva, em 13 minutos.

A entrada ao prédio foi realizada sem problemas aparentes, porém, ao realizar a segunda atividade proposta no roteiro, o participante teve bastante dificuldade. $O$ balcão de informações não foi encontrado na primeira tentativa, pois o indivíduo escolheu o lado contrário do balcão para dar início 


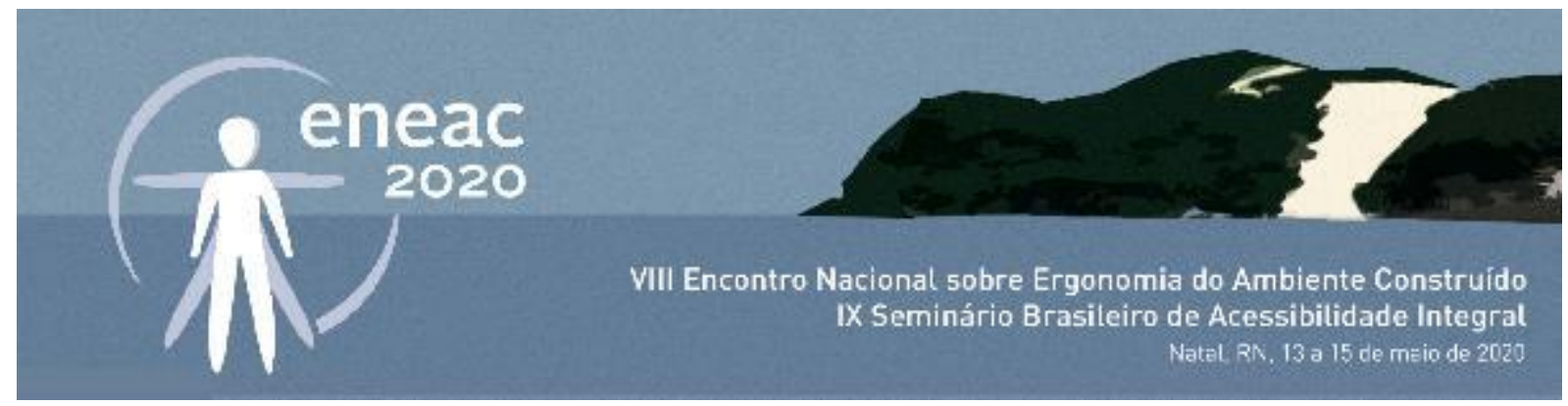

à atividade. Apesar de identificar as salas propostas com facilidade, em todos os ambientes o participante necessitava chegar muito próximo à placa para ter certeza de que era o devido local, conforme demonstrado na Figura 07.

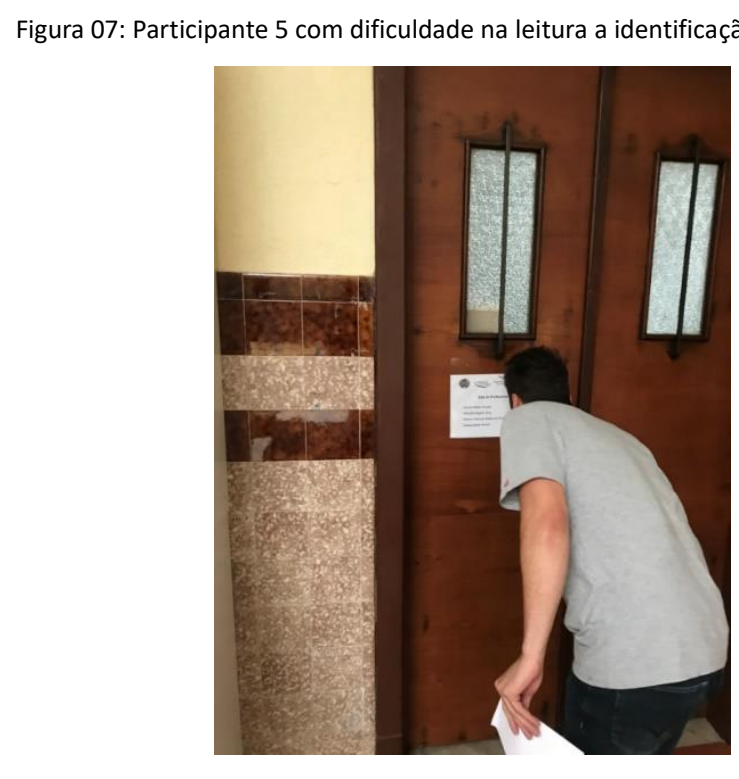

Fonte: Autores (2018).

No segundo pavimento, apesar de ocupar certo tempo para realizar todo o trajeto, identificou todos os ambientes requisitados. 0 último ambiente estabelecido no trajeto - banheiro -, não foi identificado.

Ao ser questionado sobre as condições de acessibilidade do edifício, avaliou as mesmas como medianas. Em relação à orientação espacial, o estudante abordou que faltam sinalizações com letras maiores e em cores contrastantes, uma vez que as existentes no local eram muito pequenas. Como sugestão, propôs a colocação de sinalizações nas escadas, uma vez que não há pisos direcionais no prédio auxiliando pessoas com deficiência visual na locomoção independente e segura na edificação.

\section{CONCLUSÕES}

A partir da metodologia aplicada, pode-se concluir que as condições atuais do Prédio da Alfândega não são boas. Através do passeio acompanhado, é possível observar que pessoas com alguma deficiência, limitação ou até mesmo sem restrições, têm problemas significantes ao utilizar o local. Assim, pode ser constatada a necessidade de algumas adaptações ao espaço, a partir da percepção de alguns dos usuários entrevistados.

As principais considerações são em relação ao componente orientação espacial, tendo em vista o destaque, por todos os participantes, da necessidade de instalação de placas de identificação no prédio, visto que não existe nenhuma. Em adendo a isso, exalta-se que as letras devem estar em 


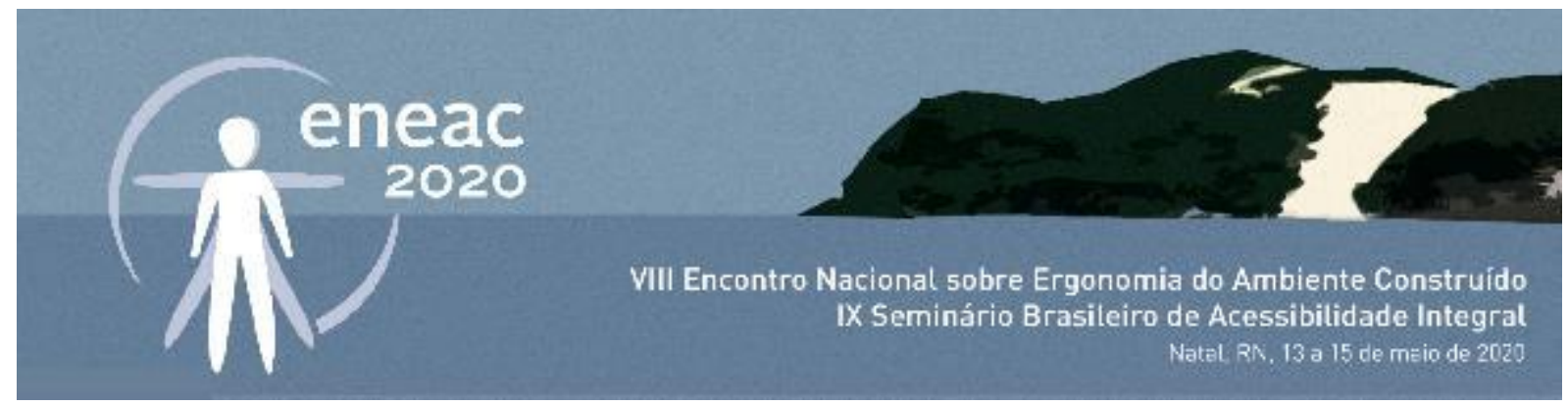

tamanhos adequados, com cores contrastantes com o fundo. A instalação de pisos táteis, associados a um mapa tátil, conforme sugerido pelos participantes do passeio, seria importante para que as pessoas possam tomar as decisões corretas de forma independente.

Em relação ao componente deslocamento é de suma importância a inserção de rampas e elevadores para o acesso e utilização de todo o espaço pelos usuários, conforme observou-se pela dificuldade de acesso do participante com o carrinho de bebê. Em relação ao componente uso, o mobiliário disponível não é adaptável a pessoas com restrições ou deficiências.

Além destas adaptações, sugere-se outros trabalhos futuros no intuito de realizar uma avaliação mais abrangente da acessibilidade neste prédio.

\section{REFERÊNCIAS}

ABNT NBR 9050. Acessibilidade a edificações, mobiliário, espaços e equipamentos urbanos. Rio de Janeiro: ABNT, 2015.

ABNT NBR 16.537. Acessibilidade - Sinalização tátil no piso - Diretrizes para elaboração de projetos e instalação. Rio de Janeiro: ABNT, 2016.

ANDRADE, I. F. Diretrizes para Acessibilidade em Edificações Históricas a partir do estudo de Arquitetura Eclética em PelotasRS. Dissertação (Mestrado em Arquitetura e Urbanismo) - Programa de Pós-Graduação,UFSC, 2009.

BINS ELY, V. H. M. Orientar-se no espaço: condição indispensável para a acessibilidade. In: Seminário Nacional Acessibilidade no Cotidiano. Rio de Janeiro. Anais. Rio de Janeiro: UFRJ, 2004.

BRASIL. Lei no 4.568 de 7 de julho de 2000. Declara área da cidade como zonas de preservação do patrimônio cultural de Pelotas - ZPPCS - lista seus bens integrantes e dá outras providências. 2000.

BRASIL. Decreto no 5.296 de 2 de dezembro de 2004. Regulamenta as Leis nos 10.048, de 8 de novembro de 2000 e 10.098 , de 19 de dezembro de 2000. Estabelece normas gerais e critérios básicos para a promoção da acessibilidade das pessoas com deficiência ou com mobilidade reduzida, e dá outras providências. 2004.

BRASIL. Lei $n^{\circ} 13.146$, de 6 de julho de 2015. Institui a Lei Brasileira de Inclusão da Pessoa com Deficiência (Estatuto da Pessoa com Deficiência). 2015.

COSTA, A. D. L.; MEIRA, A. F. A importância de formar profissionais comprometidos com a acessibilidade e a inclusão social. Programa de Pós-Graduação em Arquitetura e Urbanismo, Universidade Federal da Paraíba, 2014.

COSTA, A. D. L.; DE ARAÚJO, N. M. C. Acessibilidade no Ambiente Construído. 2 ed. João Pessoa: IFPB, 2014.

DISCHINGER, M.; BINS ELY, V. H. M.; PIARDI, S. M. D. G. Promovendo a Acessibilidade nos Edifícios Públicos: Programa de Acessibilidade às Pessoas com Deficiência ou Mobilidade Reduzida nas edificações de Uso Público. Florianópolis: Ministérios Público de Santa Catarina, 2012.

DISCHINGER, M. Designin for all senses: Accessible spaces for visually impaired citizens. Thesis for the degree of doctor of philosophy. Sweden, 2000. 260p.

FONSECA, J. J. S. Metodologia da pesquisa científica. Fortaleza: UEC, 2002.

RODEGHIERO NETO, I. Diretrizes para melhoria das condições de orientação espacial sob o ponto de vista da acessibilidade $e$ da segurança no Centro de Engenharias - UFPel. 2018, 141f. Trabalho de Conclusão de Curso - Curso de Graduação em Engenharia de Produção, CEng - Centro de Engenharias, Universidade Federal de Pelotas, Pelotas, 2018. 